DOE's Effort to Reduce Truck Aerodynamic Drag-Joint Experiments and Computations Lead to Smart Design

R.C. McCallen, K. Salari, J. Ortega, L. DeChant, B. Hassan, C. Roy, W.D. Pointer, F. Browand, M. Hammache, T.Y. Hsu, A. Leonard, M. Rubel, P. Chatalain, R. Englar, J. Ross, D. Satran, J.T. Heineck, S. Walker, D. Yaste, B. Storms

June 22, 2004

34th AIAA Fluid Dynamics Conference and Exhibit Portland, OR, United States June 28, 2004 through July 1, 2004 
This document was prepared as an account of work sponsored by an agency of the United States Government. Neither the United States Government nor the University of California nor any of their employees, makes any warranty, express or implied, or assumes any legal liability or responsibility for the accuracy, completeness, or usefulness of any information, apparatus, product, or process disclosed, or represents that its use would not infringe privately owned rights. Reference herein to any specific commercial product, process, or service by trade name, trademark, manufacturer, or otherwise, does not necessarily constitute or imply its endorsement, recommendation, or favoring by the United States Government or the University of California. The views and opinions of authors expressed herein do not necessarily state or reflect those of the United States Government or the University of California, and shall not be used for advertising or product endorsement purposes. 


\title{
DOE's Effort to Reduce Truck Aerodynamic Drag - Joint Experiments and Computations Lead to Smart Design
}

\author{
Rose C. McCallen ${ }^{1}$, Kambiz Salari ${ }^{2}$, and Jason M. Ortega ${ }^{3}$ \\ Lawrence Livermore National Laboratory, Livermore, CA 94551 \\ Larry J. DeChant ${ }^{4}$ and Basil Hassan ${ }^{5}$ \\ Sandia National Laboratories, Albuquerque, NM 87185-0825 \\ Christopher J. Roy ${ }^{6}$ \\ Auburn University, Auburn, AL 36849 \\ W. David Pointer ${ }^{7}$ \\ Argonne National Laboratory, Argonne, IL 60439 \\ Fred Browand ${ }^{8}$, Mustapha Hammache ${ }^{9}$, and Tsun-Ya Hsu ${ }^{10}$ \\ University of Southern California, LosAngeles, CA 90089-1191 \\ Anthony Leonard ${ }^{11}$, Mike Rubel ${ }^{12}$, and Philippe Chatalain ${ }^{13}$ \\ Caltech, Pasadena, CA 91125 \\ Robert Englar ${ }^{14}$ \\ Georgia Tech Research Institute, Atlanta, GA 30332
}

James Ross $^{15}$, D. Satran ${ }^{16}$, James T. Heineck ${ }^{17}$, Stephen Walker ${ }^{18}$, and D. Yaste ${ }^{19}$, B. Storms ${ }^{20}$

NASA Ames Research Center, Moffet Field, CA 94035

At 70 miles per hour, overcoming aerodynamic drag represents about $65 \%$ of the total energy expenditure for a typical heavy truck vehicle. The goal of this US Department of Energy supported consortium is to establish a clear understanding of the drag producing flow phenomena. This is being accomplished through joint experiments and computations, leading to the 'smart' design of drag reducing devices. This paper will describe our objective and approach, provide an overview of our efforts and accomplishments, and discuss our future direction.

\footnotetext{
${ }^{1}$ Engineer, Center for Applied Scientific Computing, P.O. Box 808 L-98, AIAA member.

${ }^{2}$ Engineer, New Technologies Engineering Division, P.O. Box 808 L-644, AIAA member.

${ }^{3}$ Engineer, New Technologies Engineering Division, P.O. Box 808 L-644, AIAA member.

${ }^{4}$ Engineer, Aerosciences \& Compressible Fluid Mechanics Dept., PO Box 5800 MS 0825, AIAA member.

${ }_{6}^{5}$ Manager, Aerosciences \& Compressible Fluid Mechanics Dept., PO Box 5800, MS 0825, Associate Fellow AIAA.

${ }^{6}$ Assistant Professor, Aerospace Engineering Dept., 211 Aerospace Engineering Bldg., Senior Member AIAA.

${ }^{7}$ Nuclear Engineer, Nuclear Engineering Division, NE-208, AIAA Member.

${ }^{8}$ Professor, Aerospace \& Mechanical Engineering, MS 1191, not a member.

${ }^{9}$ Research Assistant Professor, Aerospace \& Mechanical Engineering, MS 1191, not a member.

${ }^{10}$ Post Doctoral Researcher, Aerospace \& Mechanical Engineering, MS 1191, not a member.

${ }^{11}$ Professor of Aeronautics, Engineering \& Applied Science, 1200 East California Blvd. MC 301-46, not a member.

${ }_{12}^{12}$ Graduate Student, Graduate Aeronautical Laboratories, 1200 East California Blvd. MC 205-45, not a member.

${ }^{13}$ Graduate Student, Graduate Aeronautical Laboratories, 1200 East California Blvd. MC 205-45, not a member.

${ }^{14}$ Principal Research Engineer, Aerospace, Transportation \& Advanced Systems, Code 0844, Associate Fellow, AIAA.

${ }^{15}$ Deputy Chief, Systems Analysis Branch, MS 260-1, Associate Fellow, AIAA.

${ }^{16}$ Aeronautical Projects and Program Office, MS 260-1, Senior Member, AIAA.

${ }^{17}$ Aeronautical Projects and Program Office, MS 260-1, not a member.

${ }^{18}$ Aeronautical Projects and Program Office, MS 260-1, not a member.

${ }^{19}$ Aeronautical Projects and Program Office, MS 260-1, not a member.

${ }^{20}$ Aeronautical Projects and Program Office, MS 260-1, not a member.
} 


\section{Introduction}

$\mathrm{A}$ modern Class 8 tractor-trailer can weigh up to 80,000 pounds and has a wind-averaged drag coefficient around $\mathrm{C}_{\mathrm{D}}=0.6\left(\mathrm{C}_{\mathrm{D}}=\mathrm{drag} /\right.$ (dynamic pressure projected area)). More energy is consumed in overcoming aerodynamic drag as the vehicle speed increases. Figure 1 contains the estimated horsepower associated with aerodynamic drag in comparison to the power required to overcome rolling resistance and to supply needed auxiliary power, plotted as a function of speed. At 70 miles per hour, a common highway speed today, overcoming aerodynamic drag represents about $65 \%$ of the total energy expenditure for a typical heavy truck vehicle. Reduced fuel consumption for heavy vehicles can be achieved by altering truck shapes to decrease the aerodynamic resistance or drag. It is conceivable that present day truck drag coefficients might be reduced by as much as $50 \%$. This reduction in drag would represent approximately a $25 \%$ reduction in fuel use at highway speeds. An estimated total savings of $\$ 1.5$ billion per year can be recognized in the United States alone for just a $6 \%$ reduction in fuel use.

The project goal for our United States Department of Energy (DOE) supported Consortium is to establish a clear understanding of the drag producing flow phenomena through joint experiments and computations, leading to

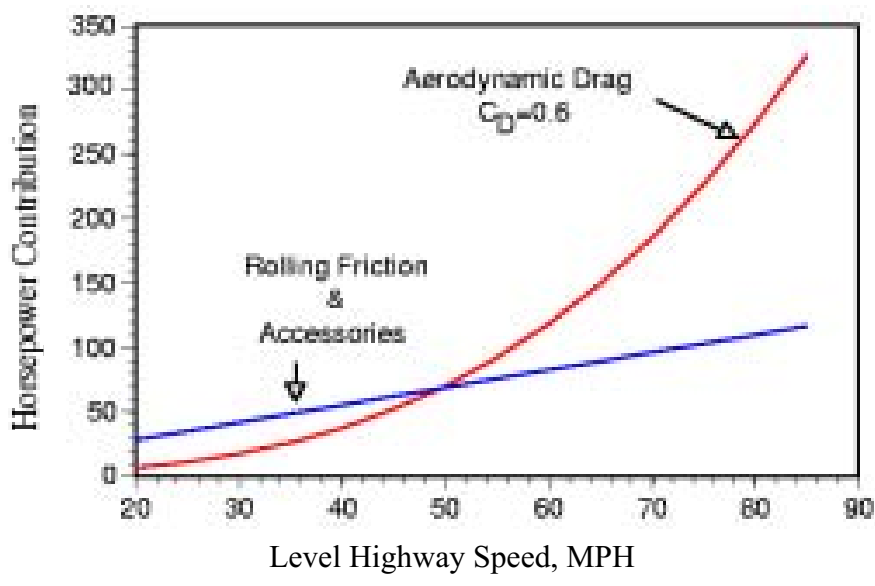

Figure 1. Horsepower required to overcome aerodynamic drag and rolling friction/accessories as a function of travel speed for a typical Class 8 tractor-trailer. the 'smart' design of drag reducing devices. As discussed in the following section, past experimental efforts by other research and development teams have usually provided only the change in overall body drag due to the installation of add-on devices. ${ }^{1}$ Local detailed flow or pressure measurements were not typically included. Without a detailed knowledge of the velocity and pressure fields, early experimenters drew conclusions on the mechanisms for drag reduction and optimized the design of addon devices by gathering overall body drag with variations in size and shape of the device. Current experimental efforts by the DOE Consortium involve the use of state-of-the-art instrumentation, measurement techniques, and diagnostics at Reynolds numbers representative of highway conditions that capture the velocity field and transient surface pressure about a tractor-trailer. These detailed and accurate results can be used to not only provide insight into the flow phenomena, but also to validate the computational models and tools. Computational efforts include the development and demonstration of the ability to simulate and analyze aerodynamic flow around heavy truck vehicles using existing and advanced computational fluid dynamics (CFD) tools. These tools can then be used, in conjunction with full-scale experiments, to guide the design refinement of devices for optimum performance. The final products are specific device concepts that can significantly reduce aerodynamic drag, and thus improve fuel efficiency, in addition to an experimental data base and validated CFD tools. The documented findings continue to provide clear guidance on methods of computational simulation and experimental modeling techniques for capturing the flow phenomena around a heavy vehicle and add-on drag reducing devices.

This DOE Heavy Vehicle Aeodynamic Drag Consortium is a collaborative effort of 7 organizations: Lawrence Livermore National Laboratory (LLNL), Sandia National Laboratories (SNL), and Argonne National Laboratory (ANL), University of Southern California (USC), California Institute of Technology (Caltech), National Aeronautics and Space Administration Ames Research Center (NASA Ames), and Georgia Tech Research Institute (GTRI) (Figure 2). The DOE Energy Efficiency and Renewable Energy, Office of FreedomCAR \& Vehicle Technologies (CAR stands for Cooperative Automotive Research), is supporting the consortium's effort.

The contributions and role of each organization in the Consortium are complimentary and sometimes overlapping to encourage close collaboration between the organizations. NASA, USC, GTRI, and LLNL all contribute to the experimental effort by conducting both wind tunnel and road experiments often in a joint effort. SNL, ANL, LLNL, and Caltech all contribute to the computational effort including computational modeling of full body aerodynamics and the investigation and design of add-on devices. SNL and LLNL have produced computational results for the integrated benchmark geometry called the Ground Transportation System (GTS) model

2

American Institute of Aeronautics and Astronautics 
(Figure 3) $)^{2,3}$, ANL for the Generic Conventional Model (GCM) (Figure 4), and LLNL for investigations of the tractor-trailer gap and trailer wake flow. Caltech has performed ground-breaking research and development of a gridless vortex method and continues to work on turbulence model development and benchmark simulations utilizing their advanced vortex method approach. USC, GTRI, NASA, and LLNL are involved in the demonstration and design optimization of devices. USC is investigating an acoustic drag reducing device that has been named 'Mozart', GTRI continues their investigation of a blowing device with wind tunnel and full-scale track testing, USC and NASA performed very detailed wind tunnel investigations of an angled-plate trailer base drag reduction device called 'base flaps' and USC is in the process of performing full-scale road tests with the base flaps in collaboration with the California Partnership for Advanced Transportation Highways (PATH), and LLNL has developed and wind tunnel tested a new concept for underbody drag reduction and has developed and computationally modeled a tractor-trailer-gap device. An overview of this work with emphasis on accomplishments are provided here and further details can be found in the sited individual and team publications in the Reference section of this paper.

As mentioned above, the DOE Consortium has investigated the flow field around the GCM geometry (Figure 4) both experimentally and computationally. The experimental data provides details of the transient tractor-trailer gap flow and wake flow due to the massively separating flow from the trailing edge of the trailer, and the computational effort continues to work towards accurately capturing the important characteristics of the wake flow. This work has provided detailed insight into the flow phenomena, which has lead to the successful development of drag reduction devices. For example, we have found that partial closure of the tractor-trailer gap with a single splitter plate is adequate in hindering the high drag situation of blow through, whereas past designs used a full closure device or the traditional cab side extenders. Evaluation of a trailer base flap device ( $\sim 15 \%$ reduction in drag) with the use of a low-boy trailer and/or side skirts $(\sim 10 \%$ reduction in drag) indicates an expected combined drag reduction of 22 to $25 \%$ (Figure 4 ). The reduction in fuel use at highway speeds is about half the reduction in drag. Thus, use of these devices should provide an 11 to $12 \%$ fuel savings which is estimated to result in a $\$ 3$ billion per year fuel cost savings in the United States.

Efforts continue in the investigation of acoustic and pneumatic devices to reduce base and separation drag, and some new ideas for reducing tractor-trailer gap and underbody drag. Plans are to continue work on the use of computational modeling and full-scale testing to refine and optimize the design of add-on devices. Future new areas being investigated are

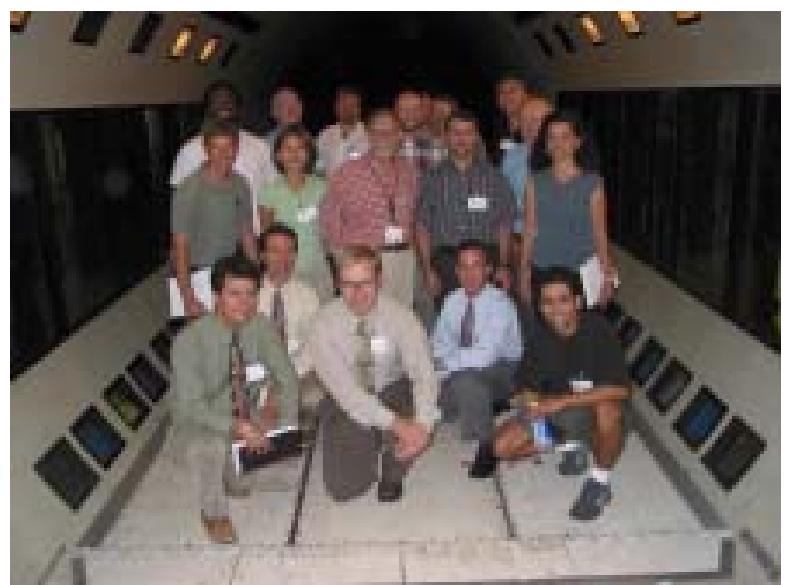

Figure 2. Consortium members in NASA Ames 12-foot pressure wind tunnel.

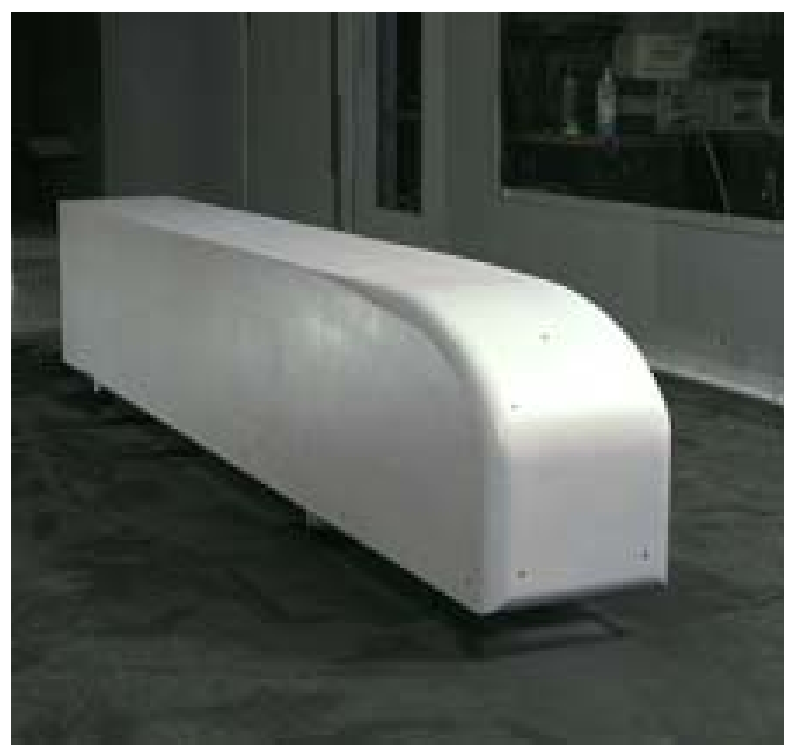

Figure 3. GTS model installed in the NASA Ames 7- by 10-Ft wind tunnel.

wheel and wheel-well aerodynamics related to brake cooling, tire splash and spray, and to determine their impact on underbody and trailer base drag reducing devices. This will involve an investigation of the flow characteristics of rotating wheels and the wheel-well and their coupling to the underbody and wake flow utilizing experiments and computations. 
This paper provides background on past experimental efforts in heavy vehicle aerodynamics, and an overview of our efforts and accomplishments. Details on how the work of the DOE consortium builds and expands on past efforts are provided, along with detailed experimental information on the flow phenomena about a tractor-trailer, as well as an added, complimentary computational modeling effort. This paper also includes a discussion of our future direction and how this includes our continued efforts to encourage the use of drag reducing technology.

\section{Background}

A wealth of information on the aerodynamics of heavy vehicles can be found in the open literature dating back to at least the early 1970's. A recent review paper by Kevin Cooper, Aerodynamics Laboratory, NRC Canada ${ }^{1}$ provides an overview of experiments performed by NRC Canada that demonstrate the benefits of drag-reducing technology. More recent work can be found in the proceedings of the UEF Conference on The Aerodynamics of Heavy Vehicles: Trucks, Buses and Trains held in Monterey, California in December of $2002^{4}$.

Almost all of the early work involved wind tunnel and road testing to investigate the effect of tractor-cab shaping or edge rounding of tractor and trailer and the performance of a range of add-on drag reducing devices. Early efforts were very successful at designing tractor-mounted aero devices or tractor-shaping with edge rounding that provided significant wind-averaged drag reductions, $\Delta \mathrm{C}_{\mathrm{D}}\left(\mathrm{V}_{\mathrm{t}}\right)$, of order 0.15 to 0.25 at truck road speeds, $\mathrm{V}_{\mathrm{t}}$, of $55 \mathrm{mph}$ which can provide fuel savings of roughly 3,000 to 5,000 US gallons per year, per truck ${ }^{1}$. Most importantly, these tractor modifications were welcomed by the industry as early as the 1980's and are evident today in the more streamline tractors with rounded edges and aero-shields. However, trailer or tractor-trailer gap mounted devices that were shown in the 1980s to provide significant drag reduction are even still not in wide use. These devices include trailer side skirts that reduce underbody drag, trailer boat-tails that reduce base drag, and tractor-trailer side extenders or mid-plain seals that reduce gap drag.

There are several possible reasons why industry has not utilized modifications that reduce base, gap, and underbody drag. Fleet operators typically purchase several trailers for every tractor, so trailer add-on devices must be more economical than a tractor add-on device to recover cost. Maintenance cost is a concern, as well as initial cost. Truck drivers can have difficulty keeping their mud flaps secured, so side skirts are considered added nuisance. In addition, side skirts can restrict access to the underside of the trailer and tractor. Most trailers have rear loading and the doors must fold completely back for dock loading and unloading. Fleet operators are concerned of the possible damage to trailer base mounted boattails that need to be moved out of the way or retracted to open rear doors, resulting in higher maintenance costs. This may also pose an additional burden on the driver. It should also be noted that up until the spring of 2002, the U.S. had regulations requiring that the trailer underslide protection or bumper had to hang off of the protruding boattail. Most boattails are made of light weight materials and are not designed to support a heavy metal bumper. Fortunately this regulation has changed so that the bumper need not be supported by the boattail. Also, boattails can protrude from the back of a trailer up to 5 feet.

As mentioned above, almost all of the early work involved wind tunnel and road testing. Computational modeling was not used to guide experiments or design. There are enormous amounts of data that consist exclusively of full-body drag coefficients measured with a force balance for wind tunnel tests and fuel consumption measurements for road tests. Local detailed flow or pressure measurements were not typically included. Without a detailed knowledge of the velocity and pressure fields, early experimenters drew conclusions on the mechanisms for drag reduction and optimized the design of add-on devices by gathering overall body drag with variations in size and shape of the device.

It was the goal of the DOE Consortium to generate a data base of detailed wind tunnel data that provides validation for computational tools, as well as insight into the flow phenomena about a tractor and trailer. To acquire the needed velocity and pressure measurements, the NASA Ames Team developed new and innovative data acquisition techniques. With the early 2002 tests in the NASA 7-ft by $10-\mathrm{ft}$ wind tunnel, the Team was one of the first to successfully use three-dimensional Particle Image Velocimetry (PIV) in a production wind tunnel. ${ }^{5}$ Per the direction of our industrial collaborators, we were encouraged to construct experiments that would determine if reduced scale and reduce Reynolds number $(\mathrm{Re})$ testing was appropriate in capturing the flow phenomena for heavy vehicles or if full-scale testing was required. In 2003, the NASA Ames 12-ft Pressure Wind Tunnel was utilized to capture detailed data for a realistic truck geometry at varying Re while maintaining a given Mach number (Ma). ${ }^{6}$

Ongoing computational modeling, combined with experimental validation, continues to provide insight into the complex bi-modal flow between the tractor and trailer and the transient wake flow with and without base drag reduction devices. The steady Reynolds-averaged Navier-Stokes (RANS) modeling approach typically used by industry has been investigated by our DOE Consortium. The results provide guidelines for use of steady RANS for 
heavy vehicle drag predictions and design of add-on devices. It has been found that the computed overall vehicle drag is highly dependent on the choice of steady RANS turbulence model. Solutions may disagree with measurements by 0.5 to $50 \%$ for 0 degree yaw and by even higher percentages at yaw angles. Thus, the performance of steady RANS models for a given geometry is not predictable and experimental results to determine accuracy are critical when relying on steady RANS for design guidance. Efforts continue into the investigation of unsteady RANS and hybrid RANS/large-eddy simulation (LES) approaches to improve predictive capabilities. Further details on our experimental, computational, and design efforts are presented in the following section of this paper.

The issue of how to introduce the drag-reducing technology to the market has been a challenge, as it was for the early investigators. The DOE Consortium continues to address this issue by encouraging and providing opportunities for interactions and communications with industry. The original DOE multi-year program plan ${ }^{7}$ was constructed and evolved based on direct input and guidance from tractor and trailer manufacturers and fleet operators through several DOE workshops with industry and visits to industry sites. The consortium participants from ANL have successfully formed an alliance with a tractor manufacturer through the support of a DOE Collaborative Research and Development Agreement (CRADA) allowing for direct interaction on our computational model development. In 2003, DOE formed a complimentary DOE Industry Consortium to work with our existing DOE Consortium of R\&D laboratories and universities. The DOE Industry Consortium is specifically tasked to address the issue of getting advanced technology on trucks. The tractor manufacturers are also strongly encouraged and do attend our working group meetings that occur once or twice a year. Involvement of fleet operators and trailer manufacturers has been much more difficult. We continue our efforts to work with the American Trucking Association to encourage dialogue with the fleet operators.

\section{Overview of Accomplishments}

The following is an overview of the DOE Heavy Vehicle Aerodynamic Drag Consortium's accomplishments in the project's 3 focus areas: ${ }^{7}$

- Drag reduction devices

- Experimental testing

- Computational modeling

Detailed reports are being provided by each participating organization as papers submitted for this $34^{\text {th }}$ AIAA Fluid Dynamics Conference.

\section{A. Drag Reduction Devices}

There are three areas identified for aero drag reduction and several drag reduction devices have been investigated (Figure 4):

- $\quad$ Tractor-Trailer Gap: Stabilizing devices, cab extenders

- Wheels/Underbody: Skirts/lowboy trailer $\left(\Delta \mathrm{C}_{\mathrm{D}} \sim 0.05\right)$, splitter plate

- Trailer Base: Boattail plates $\left(\Delta \mathrm{C}_{\mathrm{D}} \sim 0.05\right)$, base flaps $\left(\Delta \mathrm{C}_{\mathrm{D}} \sim 0.08\right)$, rounded edges, and pneumatics

The drag reduction for various device add-ons is shown in Figure 4, as a function of vehicle yaw angle. These results were obtained in the NASA Ames 12-foot Pressure Wind Tunnel (PWT) using the realistic Generic Conventional Model (GCM) geometry, tested at realistic highway Reynolds numbers $(\mathrm{Re}=1.1$ million and 6 million based on trailer width for $1 / 8^{\text {th }}$ scale model, representative of 15 and $80 \mathrm{mph}$ for a full-scale vehicle). Side and roof extenders are shown to significantly reduce the drag at high yaw. Base flaps, as shown in a close-up in Figure 5, are expected to provide 50\% more drag reduction than boattails, per comparison of wind tunnel experiments. For a tractor-trailer with a $C_{D}=0.55$ the percent drag reduction $\left(\Delta C_{D} / C_{D}\right)$ utilizing base flaps $(\sim 15 \%)$ and side skirts and/or a low-boy trailer $(\sim 10 \%)$ is estimated at 22 to 25 percent. Thus, the use of base flaps and skirts would provide an 11 to 12 percent fuel savings which should result in a $\$ 3$ billion per year fuel cost savings in the US. (Note that the cost of the device and possible maintenance over the year should also be considered for determining the overall cost savings to the fleet owner.)

The base flaps are simple flat plates mounted on the edges of the back end of a trailer. The lengths of the plates match the dimensions of the trailer base (two $11.5 \mathrm{ft}$ long plates on the sides and two $8.5 \mathrm{ft}$ long plates on the top and bottom for a full-scale vehicle). The width of the plates or how much they protrude from the trailer is about $1 / 4$ the width of the trailer or about 2 feet. Tilting the flaps about 20 degrees inward away from being flush with the trailer sides appears to provide the optimum drag reduction. The optimum flap angle for an on-road vehicle is yet to be determined, but we expect it to be near 20 degrees. 
Development has continued on tangential blowing aircraft-based technology to reduce heavy vehicle drag by eliminating aft separation on the trailer and recovering base pressure on the back doors (Figure 6). Smaller-scale tunnel results have shown measured drag reductions as high as $15 \%$ due to blowing and $10-12 \%$ due to the device's corner rounding, for a total of $25-27 \%$. Blowing also has the potential to increase drag for use in braking, to reduce drag due to side winds, and to overcome directional instabilities due to side gusts. A recorded 5-6\% fuel economy increase (not accounting for energy use for blowing) resulted from limited on-track heavy vehicle fuel economy tests. Configuration problem areas have been identified and corrected during follow-on tests, and these are now being re-tested during a second full-scale road test. Previous wind tunnel test results can be found in the referenced literature ${ }^{8}$.

Tractor/trailer model in 12' PWT

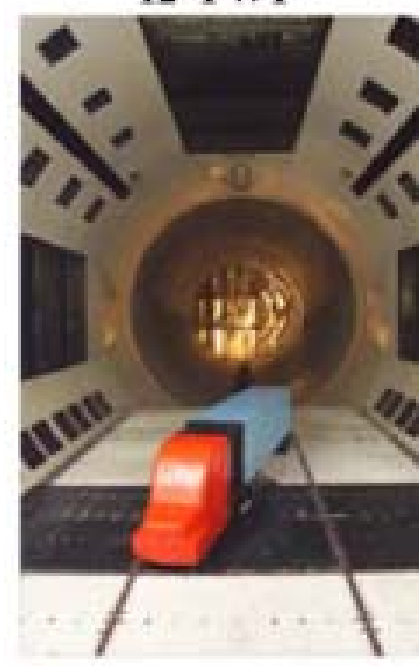

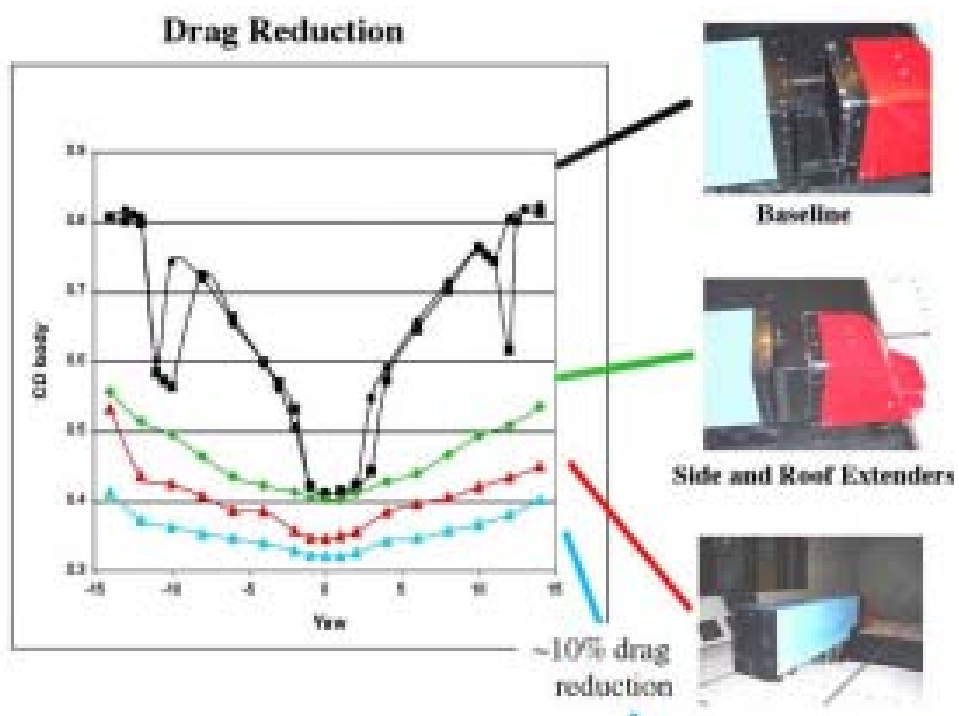

Lewhoy Trailer

Figure 4. a) Baseline GCM configuration in the NASA Ames 12, pressurized wind tunnel; and b) Drag coefficient curves for various addon drag reduction devices.

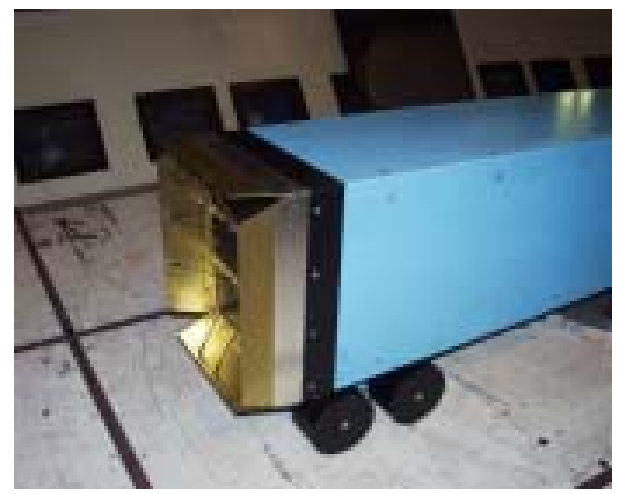

Figure 5. Base flaps (gold colored) mounted on back end of trailer (blue) in NASA Ames' 12-foot pressure wind tunnel.

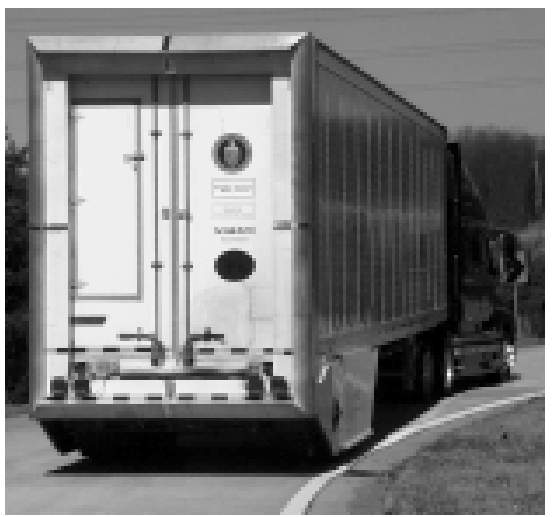

Figure 6. Pneumatic device mounted on test vehicle. 


\section{B. Experimental Findings and Suggested Guidance}

The $1 / 8^{\text {th }}$-scale Ground Transportation System (GTS) model was studied experimentally in the NASA Ames 7 - by 10 -foot Wind Tunnel (Figure 3) ${ }^{5}$. Previous tests with the GTS model were also performed in 1995 by SNL at the Texas A\&M University Low Speed Wind Tunnel ${ }^{2,3}$. Designed for validation of computational results, the GTS model has a simplified geometry with a cab-over-engine design and no tractor-trailer gap. As a further simplification, all measurements of the GTS model were made without wheels. Aerodynamic boattail plates were also tested on the rear of the trailer to provide a simple drag reduction device for computational investigation (Figure 7). Unlike the follow-on experiments performed in the NASA 12-foot Pressure Wind Tunnel (PWT), these experiments, in the 7-foot by 10 -foot tunnel, were for a low Reynolds number ( 1 million) with this simplified GTS geometry and without the control of Mach number that is possible in the PWT. (There are also experimental results for the GCM geometry in the 7-foot by 10-foot NASA Ames wind tunnel.)

The experimental measurements include body-axis drag, surface pressures, surface hot-film anemometry, oilfilm interferometry, and 3-D particle image velocimetry (PIV). Again, the purpose of obtaining this level of detail on the flow field is for computational model validation, as well as further advancing the understanding of the flow characteristics about a heavy vehicle. The goal is to then use this information and computational tools to more effectively design drag reducing design characteristics.

The wind-averaged drag coefficient with and without boattail plates was 0.225 and 0.277 , respectively. PIV measurements behind the model reveal a significant reduction in the wake size due to the flow turning provided by the boattail plates. The bottail plates have the same flow characteristics of a backward-facing step. A small recirculation zone forms in the step region behind the trailing edge of the trailer and the outside of the plate,

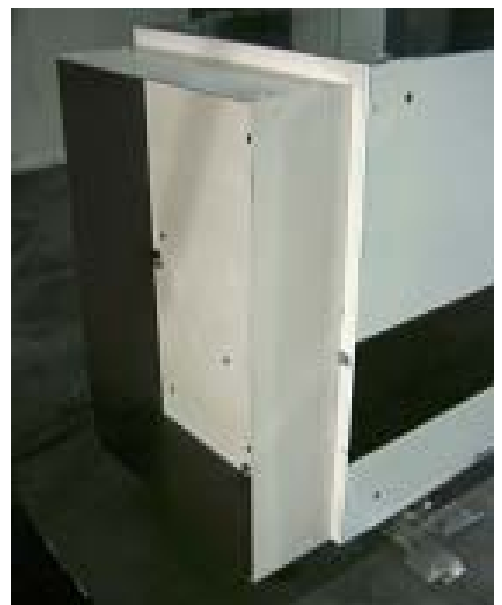

Figure 7. Photograph of boattail plates installed on rear of trailer.

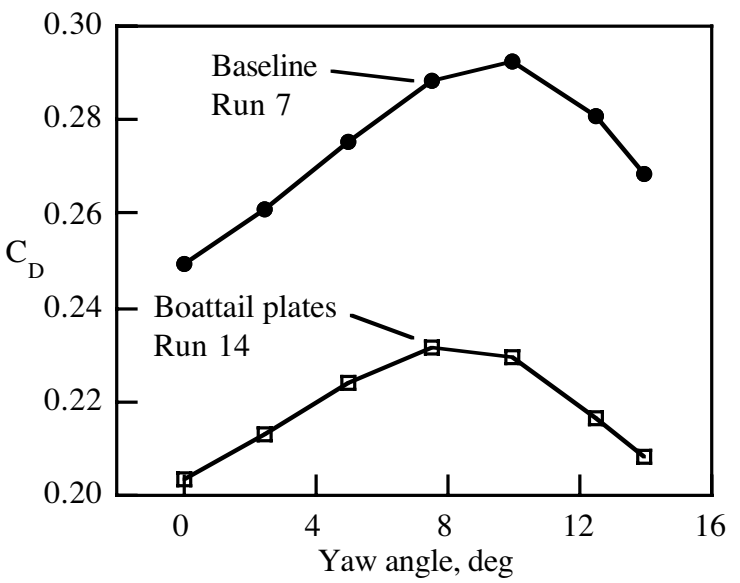

Figure 8. Effect of boattail plates on drag coefficient for $\operatorname{Re}=2$ million.

providing a low pressure region along the base edge of the trailer that turns the flow inward towards the center of the trailer base, reducing the size of the wake. Figure 8 provides the measured drag coefficient as a function of yaw angle with and without (baseline) boattail plates, demonstrating substantial drag reduction at all yaw angles with a simple base-drag device.

Hot-film measurements on the side of the cab indicate laminar separation with turbulent reattachment within 0.08 trailer width for zero and \pm 10 degrees yaw. Oil film interferometry provided quantitative measurements of skin friction and qualitative surface flow visualization. Both the hot-film and oil-film measurements provided helpful information for computational flow modeling, as well as further insight into general flow characteristics about heavy vehicles.

The methodology for calculation of the force and pressure coefficients is included in the NASA Technical Memorandum $^{5}$ to facilitate comparison between computation and experiment. The NASA Technical Memorandum also includes a complete set of the experimental data and the surface definition of the model is included on a CDROM for further analysis and comparison.

As mentioned above, experiments have been conducted on a Generic Conventional Model (GCM) in the NASA Ames 7-ft by 10-ft wind tunnel for Reynolds numbers (Re) of 1 million based on the width of the trailer, which 
corresponds to a full-scale vehicle traveling at roughly $15-\mathrm{mph}$. As also mentioned in the previous section, additional experiments have been performed on the GCM geometry in the NASA Ames 12-ft pressure wind tunnel (PWT) for Re of 1 and 6 million, where the later corresponds to a full-scale vehicle traveling at 80-mph.

Geometry configurations on the GCM in the PWT included the addition of tractor side extenders, a low-boy trailer, and boattails and base flaps on the trailer's trailing edge. The results in the PWT are obtained for a constant Mach number $(\mathrm{Ma}=0.15)$ by pressurizing the tunnel. This allows for the determination of Re and geometry effects. Yaw angles were varied from +14 to -14 degrees measured from the vehicle length axis and wind direction so that accurate wind-averaged drag could be determined, in addition to determining the effect of yaw angle. The following is a list of experimental techniques and measurements:

- Internal balance measured the vehicle forces and moments

- Load cells measured the drag for the body axis and yawing moment of the tractor

- Static pressure taps on the model (476) and taps on the walls and floor (368) measured static pressure conditions

- Unsteady pressure transducers (14) provide a pressure time history on the surface of the vehicle

- Three-dimensional PIV provided a time history of the velocity field on planes in the wake of the vehicle and in the tractor-trailer gap.

Drag measurements alone are not sufficient to provide an understanding of the impact of geometry modifications and direction for design improvements. It is recommended that advanced measurement techniques like PIV and pressure sensitive paint (PSP) be included. These advanced techniques provide important information on the global and local structure of the flow and can provide clear design direction and computational model validation. For example, in the next section, it is shown that steady RANS modeling does not capture the structure of the trailer base wake, while (for some turbulence model choices and geometries) it can capture the overall vehicle drag. In addition, as shown below, PIV measurements in the tractor-trailer gap have provided insight into the bi-modal nature of the flow and the high and low drag situations for various gap sizes, giving direction to design options for tractor-trailer gap closure devices.

Figure 9 shows the measured drag coefficient for the GCM in the PWT with and without base flaps. This figure not only shows the effectiveness of the base flaps at all yaw angles, but it also provides some insight as to Reynolds number effects. The following are the determined Re effects based on the PWT experiments with the GCM:

- $\quad$ Re effects on $C_{D}$ are in general minimal for experiments with Re above 1 million (Figure 10). This finding supports the common use of scaled down vehicles and Re below typical highway Re for experimentation.

- Some Re influence was apparent on the flow structure in the tractor-trailer gap and the back end of the trailer. It was most apparent in the upper portion of the flow region in the gap and in the wake. Thus, some inaccuracies should be considered when evaluating gap and wake drag reduction devices at lower than highway Re. For example, see difference in results for side extenders at two different Re measured in the 12-foot PWT shown in Figure 11. Low Re experiments should provide estimates, but accurate optimization of devices may require road testing.

- Edge radius effects and/or the cleanliness of the vehicle upstream flow are critical to achieving accurate predictions. Corner radii on the leading edge of the vehicle should provide $\operatorname{Re}>50,000$, based on corner radius and tunnel freestream velocity (Figure 12). Tripping the flow at the vehicle leading edge may also be required to avoid flow separation (Figure 13).

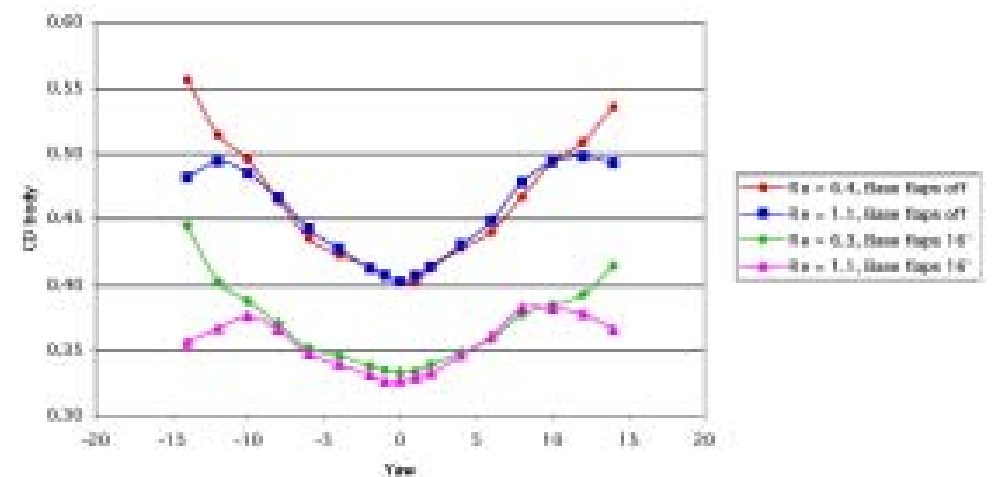

Figure 9. Drag coefficient versus yaw angle with and without base flaps for $R e=1.1$ million and 6 million.

8

American Institute of Aeronautics and Astronautics 


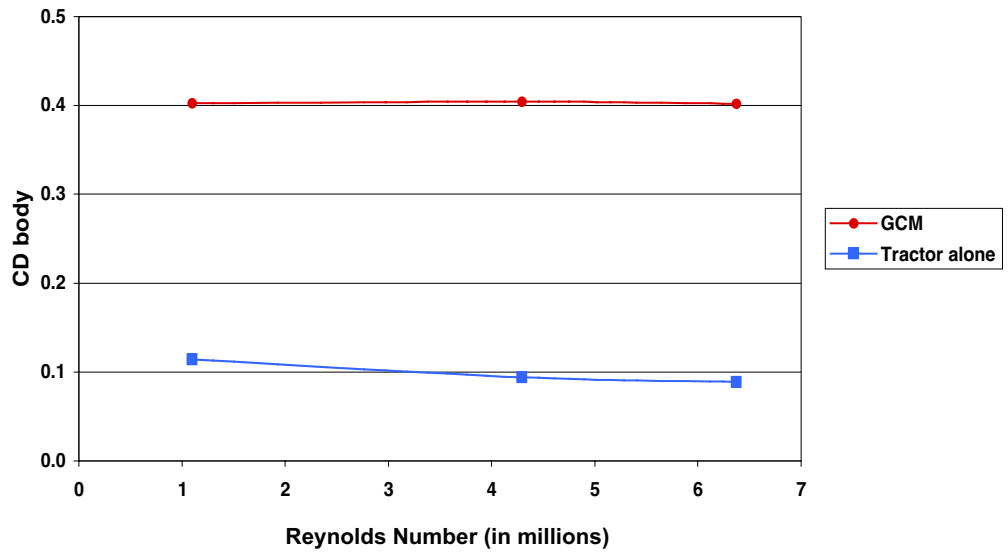

Figure 10. Drag versus Reynolds number for the GCM at zero yaw in the 12-foot PWT
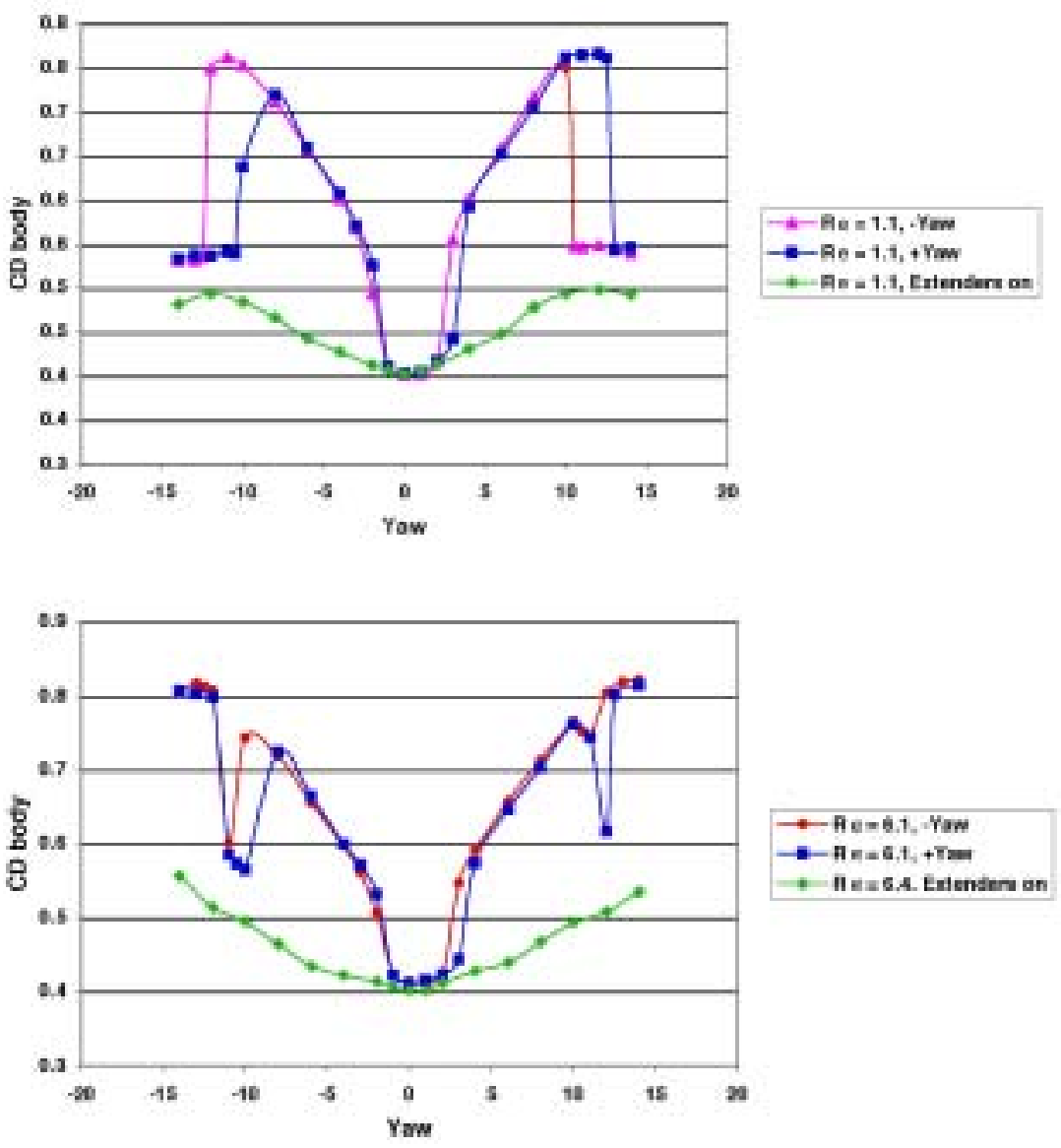

Figure 11. Examples of Re effects in trailer gap with side extenders measured with GCM in 12-foot PWT.

9

American Institute of Aeronautics and Astronautics 


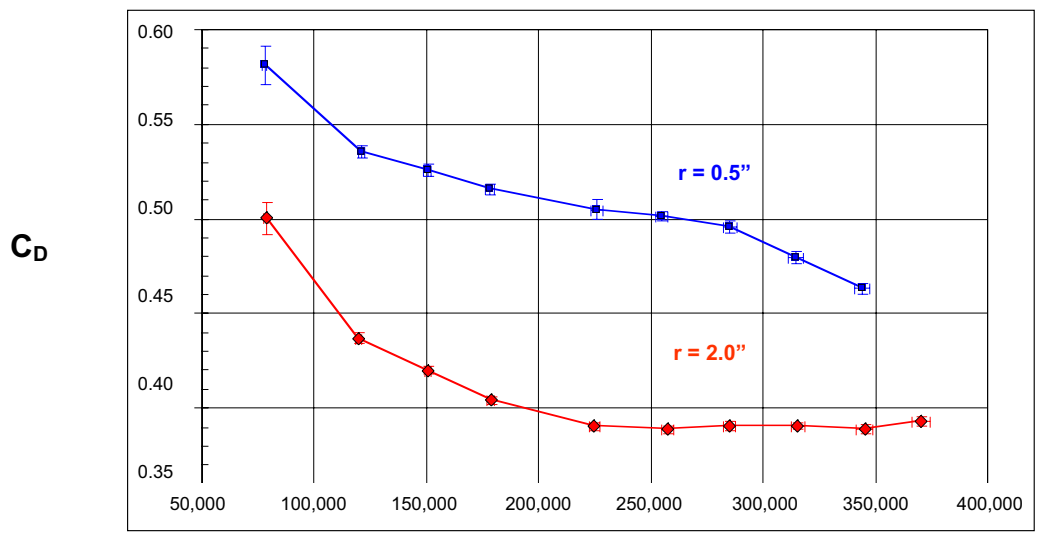

Area Reynolds number

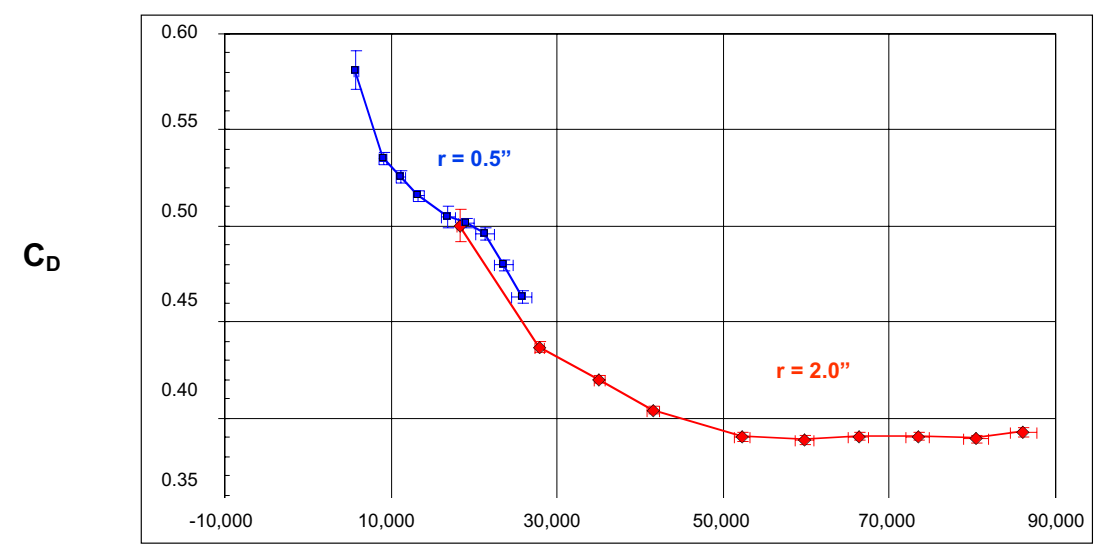

Edge Reynolds number

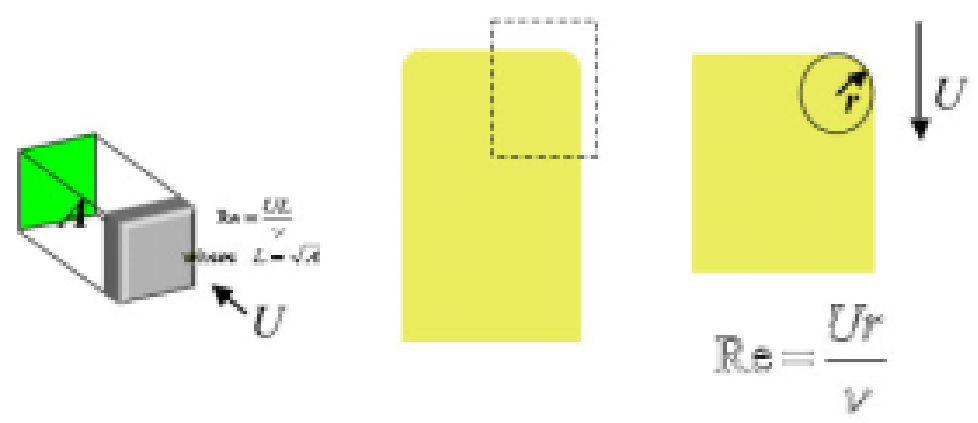

Figure 12. Effect of front edge radius on drag of isolated cab where' $r$ ' is the radius of curvature for the front edges of the GTS geometry.

American Institute of Aeronautics and Astronautics 


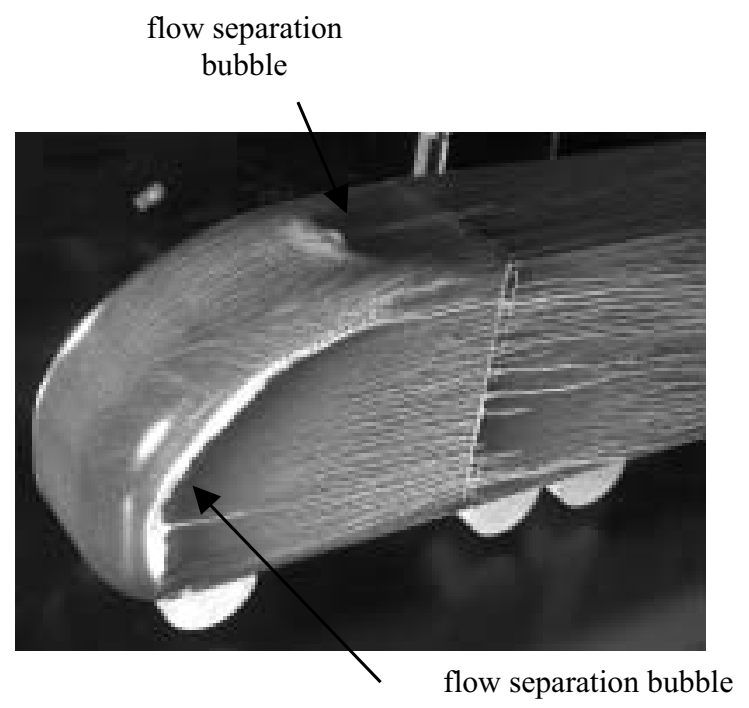

boundary layer

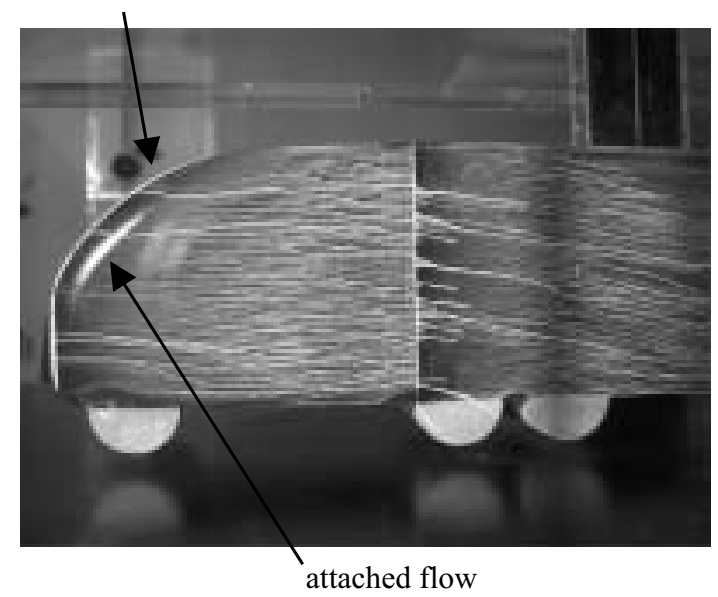

Figure 13. Means of assuring attached flow on front of GTS geometry by triping flow (figure on right).

\section{Computational Findings and Suggested Guidelines}

Team members from LLNL, SNL, ANL, and Caltech are investigating a wide range of turbulence models including steady and unsteady Reynolds-averaged Navier-Stokes (RANS and URANS, respectively), large-eddy simulation (LES), and hybrid methods that use a combination RANS and LES models in the simulation. In addition, various numerical approaches are being considered including finite volume, finite element, and vortex methods. The focus thus far has been steady RANS with and without the use of wall functions. Wall functions provide an approximation to the flow field in the wall region and the boundary layer is not resolved.

Flow simulations of the GTS model at $0^{\circ}$ and $10^{\circ}$ yaw in the NASA Ames's 7-foot by 10 -foot wind tunnel and the modified GTS with the non-dimensional gap distance of 0.72 at $0^{\circ}$ yaw in the USC tunnel have been generated and analyzed. Steady and unsteady RANS flow simulations are performed with NASA's Overflow code ${ }^{9}$ that uses overset grids and the Sandia SACCARA code ${ }^{10,11}$ that uses multi-block, structured grids. For all GTS simulations in the NASA wind tunnel, the flow condition is obtained from the available experimental data: Mach number 0.28 , Reynolds number $2.08 \times 10^{6}$ (based on trailer width), total pressure $102649.2 \mathrm{~N} / \mathrm{m}^{2}$, total temperature $284.5 \mathrm{~K}$, static pressure $97339.1 \mathrm{~N} / \mathrm{m}^{2}$, static temperature $280.2^{\circ} \mathrm{K}$, and air density 1.206 $\mathrm{kg} / \mathrm{m}^{3}$.

Figure 14 shows a complex flow field with multiple vortical structures and a separation bubble at the leeward side of the vehicle highlighted by particle traces around the GTS geometry at

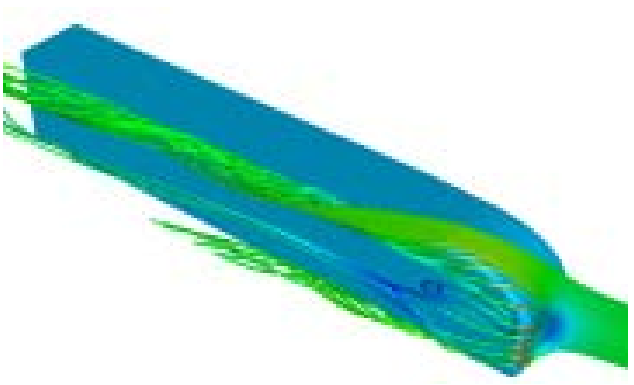

Figure 14. Particle traces for the GTS model at $10^{\circ}$ yaw. $10^{\circ}$ yaw in the NASA Ames's 7-foot by 10-foot wind tunnel.

Table 1 provides the computed drag coefficient and the experimentally measured drag values. The subscript $\mathrm{W}$ refers to the static pressure measured on the test-section tunnel wall and the subscript $\mathrm{R}$ refers to the static pressure measured upstream of the test section ${ }^{5}$. The drag coefficients obtained from the simulations are based on the dynamic pressure calculated using the test section dynamic pressure. All turbulence models have similar predictions for viscous drag; however, the one-equation Spalart-Almaras (SA) and Menter k- $\omega$ (SST) models significantly overpredict the pressure drag. Similarly, the Wilcox k- $\omega$ model over predicts the pressure drag, but provides a drag coefficient closest to the experimental value. All tested RANS turbulence models have difficulty with predicting the experimentally measured pressure drag. Since the trailer wake has a significant influence on the pressure drag, this suggests that RANS turbulence models could have difficulty predicting the correct flow structure in the wake of the trailer. 
Figure 15 shows a velocity vector field in the wake of the GTS trailer at the symmetry plane with SST turbulence model. Figure 16 shows the time-averaged PIV data from NASA Ames at the same cut plane as that in Figure 15. In the experimental data, there is a dominant recirculation zone at the lower base of the trailer. In contrast, there are two similarly sized recirculation zones on the lower and the upper part of the base of the trailer in the computational result. Noticeably, the flow structures in the computational result do not match that of the experimental PIV data and, hence, this difference may explain the disagreement in the predicted drag. The Wilcox $k-\omega$ model has a similar wake prediction as that of the SST model; however, the SA model predicts a much smaller wake size with two symmetric recirculation zones at the lower and the upper part of the base of the trailer.

The RANS models used in this study did a reasonable job in predicting the pressure and skin friction distributions on the surface of the GTS. However, if absolute drag and predicting the wake flow structure is of interest, other more sophisticated turbulence models should be investigated.

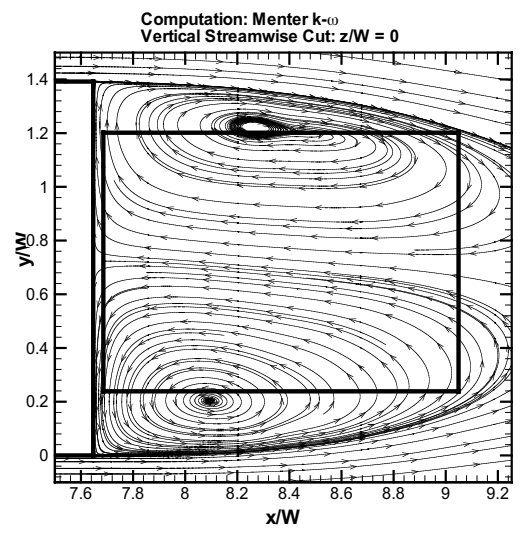

Figure 15. Wake flow structure computed with the SST model at the symmetry plane for the GTS model at $0^{\circ}$ yaw.

\begin{tabular}{|c|c|c|c|}
\hline Drag & Viscous & Pressure & Tota \\
\hline$k-\omega, \mathrm{cg}$ & 0.103 & 0.188 & 0.290 \\
\hline$k-\omega, \mathrm{mg}$ & 0.101 & 0.176 & 0.277 \\
\hline SST, cg & 0.091 & 0.273 & 0.364 \\
\hline SST,mg & 0.092 & 0.258 & 0.350 \\
\hline Menter k- $\omega$, cg & & & 0.474 \\
\hline Menter k- $\omega$, mg & & & 0.298 \\
\hline $\mathrm{SA}, \mathrm{mg}$ & 0.096 & 0.294 & 0.390 \\
\hline \multicolumn{3}{|c|}{ NASA Experiment, $C_{D, W}$} & 0.249 \\
\hline \multicolumn{3}{|c|}{ NASA Experiment, $C_{D, R}$} & 0.263 \\
\hline
\end{tabular}

Table 1. Computed aerodynamic forces for GTS model at $0^{\circ}$ yaw for a coarse grid $(\mathrm{cg})$ and medium grid (mg).

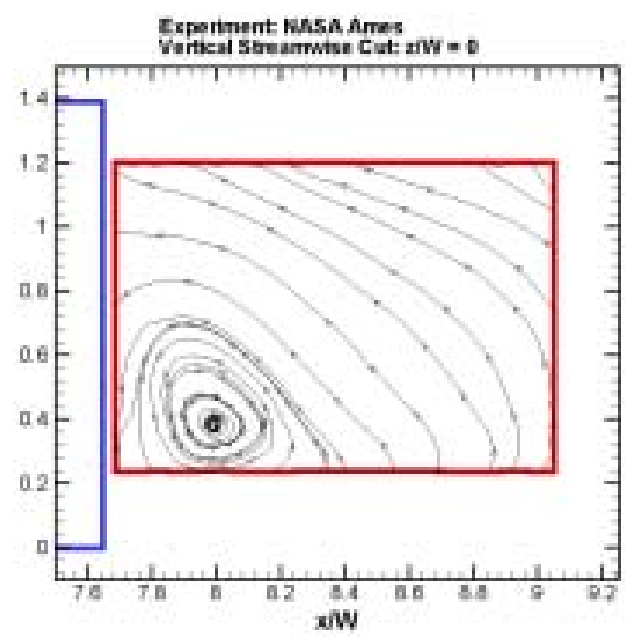

Figure 16. Wake flow structure for the NASA time averaged PIV data at the symmetry plane for the GTS model at $0^{\circ}$ yaw. 


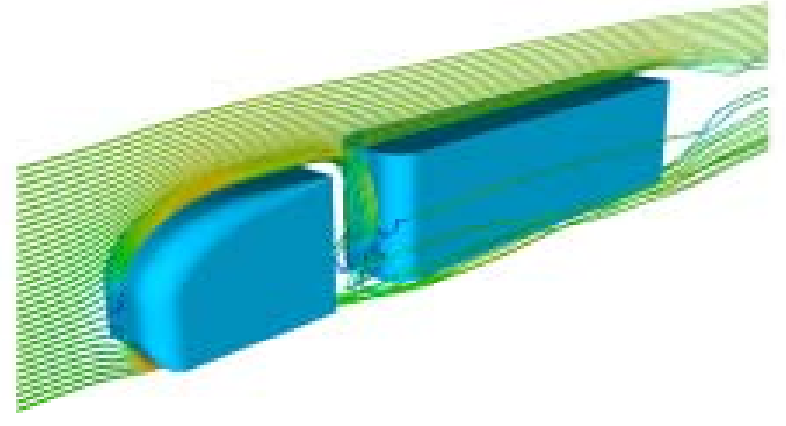

Figure 17. Particle traces colored by velocity magnitude computed with the $k$ $\omega$ model for the modified GTS geometry at $0^{\circ}$ yaw with 0.72 gap size.

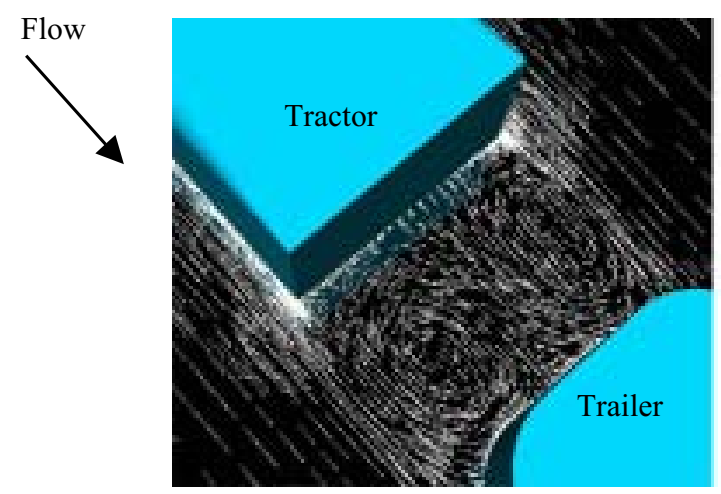

Tractor

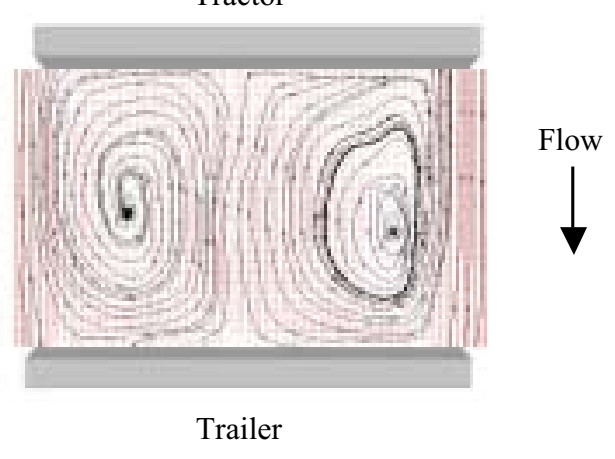

a) Computation (left image), USC experiment (right image), Symmetric condition
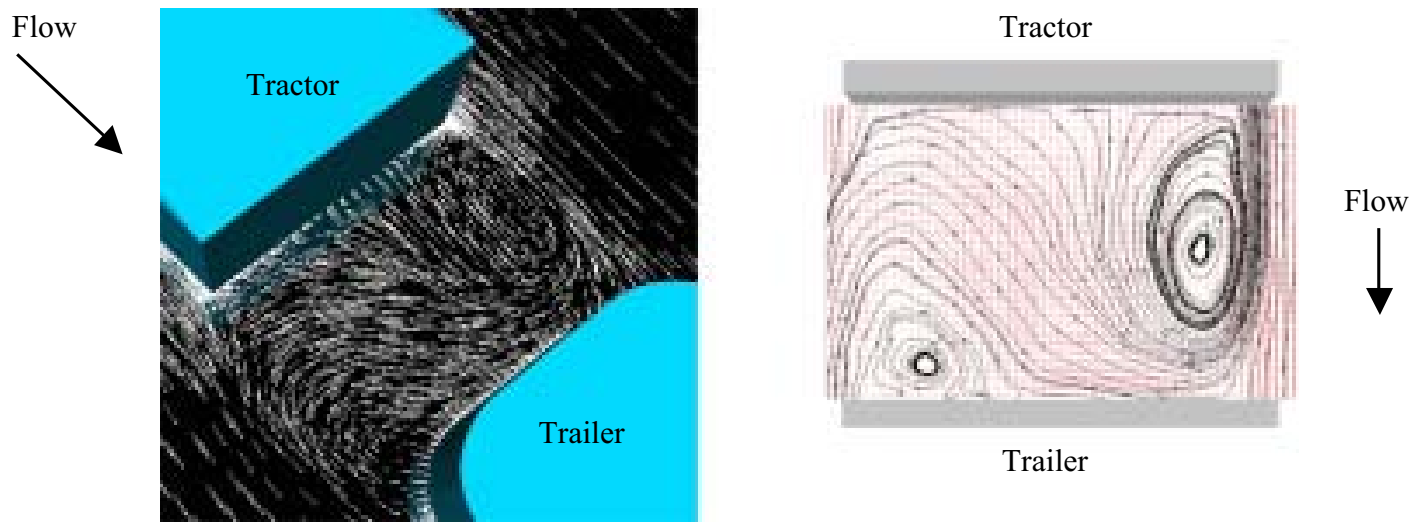

b) Computation (left image), USC experiment (right image), Asymmetric condition

Figure 18. Comparison of computed and USC experimental data at the gap mid-height at $0^{\circ}$ yaw computed with the k- $\omega$ model for the modified GTS geometry with 0.72 gap size.

Unsteady RANS simulations were conducted on the USC modified GTS geometry with a normalized gap distance of 0.72 , which is above the critical gap distance of $0.5 .^{12}$ (The USC geometry has a more rounded nose than that at the standard GTS geometry to prevent premature separation for low Re experiments.) At this gap distance, the flow experiences unsteadiness and could have multiple stable modes that are either symmetric or asymmetric. Also, the drag contribution from the gap flow significantly increases due to this unsteady behavior. Low drag for the gap relates to stable symmetric flow and high drag relates to the unsteady asymmetric flow. Figure 17 presents a snapshot of the unsteady flow field around the modified GTS model highlighted by particle traces colored by velocity magnitude. This figure shows the external flow reaching into the gap and exiting on the side. This is the 
typical unsteady asymmetric flow representing a high drag situation. The unsteady RANS simulation conducted with Overflow is capturing the symmetric and asymmetric flow field in the gap as shown in Figure 18. This figure compares the computed results with the USC experimental data.

We are also developing guidelines for the accurate prediction of heavy vehicle aerodynamic drag coefficients using commercial CFD software. In these studies, computational predictions from the commercial CFD code Star- $\mathrm{CD}^{13}$ are being compared with detailed velocity, pressure and force balance data from experiments completed in the 7-foot. by 10 -foot wind tunnel at NASA Ames ${ }^{14,15}$ using the GCM geometry. The pressure distribution along the vehicle surface using a half-vehicle model with a near-vehicle cell size of $8 \mathrm{~mm}$, a near-wall cell size limit of 0.5 $\mathrm{mm}$ and the Menter k- $\omega$ SST model with a wall function is shown in Figure 19.

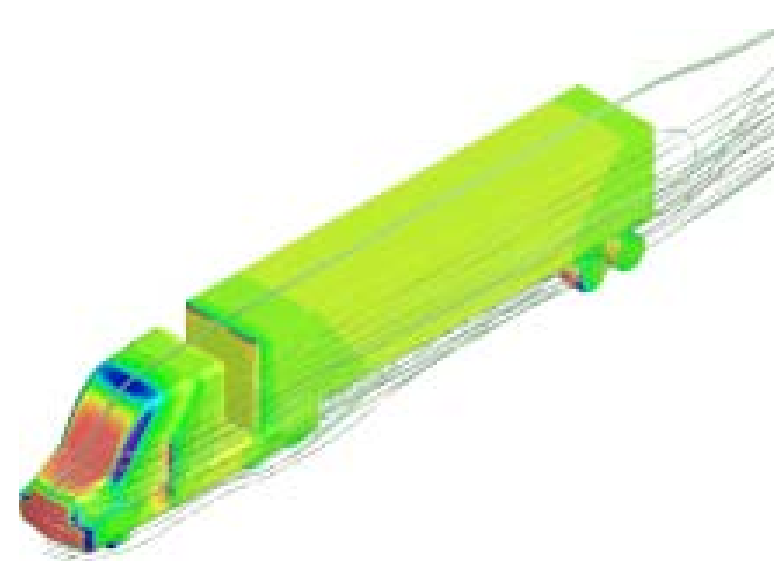

Figure 19. Surface contour plot showing the predicted surface pressure distribution along the surface of the GCM. Areas shown in red are areas of peak positive pressure and areas shown in blue are areas of peak negative pressure. Selected flow streamlines are also shown to illustrate the movement of air over the vehicle.
The following are the general observations and guidelines for steady RANS modeling:

- Conclusions on predictive capability of a turbulence model can only be determined with grid converged solutions. Predicted flow structures in separated regions, like the trailer wake, vary significantly with grid refinement. Variation in overall drag is not substantial but still apparent with grid refinement.

- When using wall functions, the first wall point should be held fixed while refining the grid (i.e., the distance from this grid point to the wall should not change), but it is appropriate to decrease the width of the wall elements while refining the grid (i.e., refinement in direction tangent to walls).

- The computed overall vehicle drag is highly dependent on the choice of turbulent steady RANS model. Solutions may disagree with measurements by 0.5 to $50 \%$ for 0 degree yaw and by even higher percentages at yaw angles. Thus, the performance of steady RANS models for a given geometry is not predictable and experimental results to determine accuracy is critical when relying on steady RANS for design guidance.

- Steady RANS models generally can capture the flow on the front and sides of the vehicle, where the flow stays attached and does not exhibit separation and recirculation zones.

- The flow structure in the trailer wake presented by the time-averaged experimental data does not compare with that computed with the steady RANS models. The trailer wake is a region of transient full flow separation and large recirculation zones. Thus, use of steady RANS to evaluate drag reduction devices in the trailer wake and tractor-trailer gap may provide inaccurate design guidance.

Near term plans are to organize similar types of guidelines related to the performance of unsteady RANS, LES, and hybrid models.

We also continue to pursue the development of vortex particle methods for heavy vehicle aerodynamics. These methods have evolved rapidly in the past ten years and have the benefit of requiring only a surface mesh on the vehicle. Preliminary LES-type simulations, using a vortex method, of flow past the GTS configuration are promising. ${ }^{16,17}$

\section{Conclusions and Future Direction}

The DOE Heavy Vehicle Aero Drag Team has modeled the flow field around a generic conventional model both experimentally and computationally. This effort has provided detailed insight into the flow phenomena, which has lead to the successful development of drag reduction devices. Evaluation of a base flap drag device $(\sim 15 \%$ drag reduction) with the use of a low boy trailer and/or side skirts $(\sim 10 \%$ drag reduction) indicates an expected drag 
reduction of 22 to $25 \%$. Use of these devices should provide an 11 to 12 percent fuel savings which is estimated to result in a $\$ 3$ billion per year fuel cost savings in the US.

To recognize these levels of fuel savings by the effective use of drag reduction devices, the involvement and acceptance by tractor manufacturers, trucking associations, fleet owners, and drivers is critical. Our DOE Consortium continues to solicit input and feedback from these organizations for design and effective use of drag reducing technology.

Future plans are to continue to develop and evaluate drag reducing conceptual designs computationally and encourage and work with industry to road test the most promising drag reducing devices. Road tests with base flaps and SAE track tests with the pneumatic device are planned for fiscal year 2004.

There are several characteristics that are not being captured in our wind tunnel testing that may be more easily captured with full-scale road testing. For example, the influence of the stationary road and the moving truck are not being captured in our stationary floor and stationary vehicle wind tunnel experiments. It may be important to investigate this influence for underbody and base drag reducing devices, like side skirts and base flaps, to determine the effect of tire rotation, underbody to road clearances, and to determine optimum shaping. Road testing the drag reduction devices provides

- On-road fuel savings

- Optimal flap deflection angle for various tractor-trailer geometries

- Optimal flap shape, length

- Optimum skirt height, shape

- Durability, practicality, safety, ease of operation of proposed devices

- Impact on truck braking capability

It is recommended that road testing include

- Instantaneous broadcast fuel rate (1/2 second updates)

- Repeated forward and back trip runs over known, instrumented highways (e.g., South-to-North and North-to-South runs)

- The use of SAE Standards

Plans are to demonstrate "actual" fuel savings from road tests and attempt to interest OEMs in collaborating on this testing effort.

Efforts continue in the investigation of acoustic ${ }^{18}$ and pneumatic devices to reduce base and separation drag, and some new ideas for reducing tractor-trailer gap and underbody drag. Plans are to continue work on the use of computational modeling and full-scale testing to refine and optimize the design of add-on devices. Future new areas being investigated are wheel and wheel-well aerodynamics related to brake cooling, tire splash and spray, and to determine their impact on underbody and trailer base drag reducing devices. This will involve an investigation of the flow characteristics of rotating wheels and the wheel-well and their coupling to the underbody and wake flow utilizing experiments and computations.

Data reduction and analysis of the experimental data for the GCM geometry continues and computations of flow around the GCM geometry will continue to be compared to this experimental data and analyzed, so that guidance can be provided on use of unsteady RANS and hybrid RANS/large-eddy simulation methods.

\section{Acknowledgments}

The Consortium members would like to thank the DOE Energy Efficiency and Renewable Energy, Office of FreedomCAR \& Vehicle Technologies for their continued support, and acknowledge Dr. Sidney Diamond, Technical Area Development Specialist, and Dr. Jules Routbort, Senior Scientist and Technical Program Manager for Heavy Vehicle Systems, for having the vision and providing the direction to form this consortium effort. Their continued enthusiastic support is greatly appreciated. The Team would also like to express our gratitude to our Project administrator at LLNL, Helen Magann, for her attention to details, endless scheduling of meetings, and assistance with documents and presentations.

This work was performed under the auspices of the U.S. Department of Energy by the University of California, Lawrence Livermore National Laboratory under Contract No. W-7405-ENG-48.

Sandia is a multiprogram laboratory operated by Sandia Corporation, a Lockheed Martin Company, for the United States Department of Energy's National Nuclear Security Administration under contract DE-AC04-94AL85000. 
The submitted manuscript has been created by the University of Chicago as Operator of Argonne National Laboratory ("Argonne") under Contract No. W-31-109-ENG-38 with the U.S. Department of Energy.

\section{References}

${ }^{1}$ Cooper, K. R., "Truck Aerodynamics Reborn - Lessons from the Past," Proceedings of the 2003 SAE International Truck and Bus Meeting and Exhibition, Fort Worth, Texas, November 10-12, 2003, SAE Technical Paper Series, 2003-01-3376.

${ }^{2}$ Gutierrez, W. T., Hassan, B., Croll, R. H., and Rutledge, W. H., "Aerodynamics Overview of the Ground Transportation Systems (GTS) Project for Heavy Vehicle Drag Reduction,” SAE Paper No. 960906, SP 1145, 1996.

${ }^{3}$ Croll, R. H., Gutierrez, W. T., Hassan, B., Suazo, J. A., and Riggins, A. J., "Experimental Investigation of the Ground Transportation System (GTS) Project for Heavy Vehicle Drag Reduction,” SAE Paper No. 960907, SP 1145, 1996.

${ }^{4}$ McCallen, R. C., Browand, F., Ross, J. C. (eds.), The Aerodynamics of Heavy Vehicles: Trucks, Buses and Trains, Lecture Notes in Applied and Computational Mechanics, Vol. 19, Springer-Verlag, Heidelberg, to be published August 2004.

${ }^{5}$ Storms, B. L., Ross, J. C., Heineck, J. T., Walker, S. M., Driver, D. M., and Zilliac, G. G., "An Experimental Study of the Ground Transportation System (GTS) Model in the NASA Ames 7- by 10-Ft Wind Tunnel," NASA TM-2001-209621, February 2001.

${ }^{6}$ Storms, B. L., Satran, D. R., Heineck, J. T., and Walker, S. M. "A Study of Reynolds Number Effects and Drag-Reduction Concepts on a Generic Tractor-Trailer," AIAA Paper 2004-2251, 24th AIAA Aerodynamic Measurement Technology and Ground Testing, June 2004.

${ }^{7}$ McCallen, R. C., Browand, F., Rutledge, W., Ross, J. C., Leonard, A., A Multi-Year Program Plan for the Aerodynamic Design of Heavy Vehicles, Heavy Vehicle Aerodynamic Drag Project [online publications], URL: http://eed.llnl.gov/aerodrag/pdf/mypp.pdf [cited May 1998]

${ }^{8}$ Englar, R. J., "Advanced Aerodynamic Devices to Improve the Performance, Economics, Handling and Safety of Heavy Vehicles," SAE Paper No. 2001-01-2072, Washington, DC, May 14-16, 2001.

${ }^{9}$ Overflow Code, version 1.8s, NASA Ames Research Center.

${ }^{10}$ Wong, C. C., Soetrisno, M., Blottner, F. G., Imlay, S. T., and Payne, J. L., "PINCA: A Scalable Parallel Program for Compressible Gas Dynamics with Nonequilibrium Chemistry," SAND 94-2436, Sandia National Laboratories, Albuquerque, NM, 1995.

${ }^{11}$ Roy, C. , D. Kuntz, M.A. McWherter-Payne, J.L. Payne, "RANS Simulations of a Simplified Tractor/Trailer Geometry," The Aerodynamics of Heavy Vehicles: Trucks, Buses and Trains, edited by R. C. McCallen, F. Browand, and J. C. Ross, Lecture Notes in Applied and Computational Mechanics, Vol. 19, Springer-Verlag, Heidelberg, to be published August 2004.

${ }^{12}$ Hammache, M., Browand, F., "On the Aerodynamics of Tractor-Trailers", The Aerodynamics of Heavy Vehicles: Trucks, Buses and Trains, edited by R. C. McCallen, F. Browand, and J. C. Ross, Lecture Notes in Applied and Computational Mechanics, Vol. 19, Springer-Verlag, Heidelberg, to be published August 2004.

${ }^{13}$ Star-CD, version 3.150A, CD-Adapco Group, Melville, NY.

${ }^{14}$ D. Satran, "An Experimental Study of the Generic Conventional Model (GCM) in the NASA Ames 7-by-10-Foot Wind Tunnel," The Aerodynamics of Heavy Vehicles: Trucks, Buses and Trains, edited by R. C. McCallen, F. Browand, and J. C. Ross, Lecture Notes in Applied and Computational Mechanics, Vol. 19, Springer-Verlag, Heidelberg, to be published August 2004.

${ }^{15}$ Heineck, J. T., Walker, S., Satran, D., "The Measurement of Wake and Gap Flows of a 1/8th Scale Generic Truck Using Three-Component Particle Image Velocimetry," The Aerodynamics of Heavy Vehicles: Trucks, Buses and Trains, edited by R. C. McCallen, F. Browand, and J. C. Ross, Lecture Notes in Applied and Computational Mechanics, Vol. 19, Springer-Verlag, Heidelberg, to be published August 2004.

${ }^{16}$ G. Daeninck, G., Chatelain, P., Rubel, M., Winckelmans, G., A. Leonard, "Simulation of Vehicle Aerodynamics using a Vortex Element Method," The Aerodynamics of Heavy Vehicles: Trucks, Buses and Trains, edited by R. C. McCallen, F. Browand, and J. C. Ross, Lecture Notes in Applied and Computational Mechanics, Vol. 19, Springer-Verlag, Heidelberg, to be published August 2004

${ }^{17}$ Kamenmoto, K., Ojima, A., "Applicability of the Vortex Methods for Aerodynamics of Heavy Vehicles," The Aerodynamics of Heavy Vehicles: Trucks, Buses and Trains, edited by R. C. McCallen, F. Browand, and J. C. Ross, Lecture Notes in Applied and Computational Mechanics, Vol. 19, Springer-Verlag, Heidelberg, to be published August 2004.

${ }^{18}$ Hsu, T.-Y., Browand, F., Hammache, M., "Base Flaps and Oscillatory Perturbations to Decrease Base Drag", The Aerodynamics of Heavy Vehicles: Trucks, Buses and Trains, edited by R. C. McCallen, F. Browand, and J. C. Ross, Lecture Notes in Applied and Computational Mechanics, Vol. 19, Springer-Verlag, Heidelberg, to be published August 2004. 